\title{
Game Theory Based Research on Profit Distribution among Stakeholders in Urban Renewal Projects
}

\author{
Jingjing Liu ${ }^{1, a}$, Yuqi Zou ${ }^{2, b}$ \\ ${ }^{1}$ School of Civil Engineering and Architecture, Wuhan University of Technology, Wuhan, Hubei, \\ 430070, China \\ ${ }^{2}$ Wuhan Langold real estate co., LTD, Wuhan, Hubei, 430070, China \\ ae-mail: whut2007_jing@163.com, be-mail: ZYQ_nanguo@163.com
}

Keywords: Urban renewal; Housing demolition; Profit distribution; Game equilibrium

\begin{abstract}
Always encountered at the demolition stage in an urban renewal project are conflicts among the stakeholders including the government agency, the original residents and the real estate developer. In order to mediate their different interests, a reasonable demolition compensation system is undoubtedly of great importance. From the perspective of profit distribution game theory, the relationships among stakeholders in urban housing demolition compensation system are discussed, the static game model among three parties is constructed and the profit distribution mechanism based on reciprocating fairness is analyzed. Through the study of the paper, the cooperative equilibrium among the three parties is found and the criteria of profit distribution are put forward.
\end{abstract}

\section{Introduction}

The most difficult task in a renewal project is how to construct a reasonable compensation system during the demolition period. Besides the compensations to the original residents, the developer also pays for the ancillary facilities, such as municipal pipeline, which is usually enormous. For instance, in the Peace avenue of Beijing urban renewal, the cost of housing demolition accounted for 83\% of the total investment; and in Shanghai Bin Jiang Garden Project developed by Shimao Group, the compensation cost was 2 billion RMB. It is revealed by certain statistics that in China the demolition compensation in an urban renewal project usually accounts for more than $50 \%$ of the total investment [1].

In order to balance the stakeholders' expected profits so as to achieve a win-win game, a lot of researches have been carried out by both academicians and industrials. Liu Li and Zou Yi combine some exploitation cases to analyze the dilemma of urban renewal, and the successful solution to these problems is the most significant factor for the project's success [1]. Zhu Dongkai and Shi Guoqing find the root causes of contradiction during the hosing demolition, through analyzing the interest relationship in land acquisition and demolition of urban construction [2]. Wang Da scholar finds some problems from searching enforcing behaviors during the housing demolition [3]. In recent years, many scholars just as Zhang Bo aim at the underlying problems and reasons in urban renewal to analyze the complex relationship among stakeholders based on Game theory[4]. Moreover, Yao Yan-hong scholar finds some countermeasures for the problems in housing demolision based on Game analysis [5].

Many practical facts teach us that the way of pursuing the profit maximization of our own cannot resolve the social and economic problems. Therefore, the game model of fair reciprocity has an important application prospect. Rabin firstly successful add the concept of fair in the Game theory and economics. The fairness equilibrium fully explains the motivation of fair reciprocity under the strategic reciprocal environment. The thinking venation of Rabin is similar to that of Kahneman's behavioral economics [6]. Sun Shi-zhe extends several important game models of fair reciprocity based on the studies of predecessors [7]. In addition, Guo Bin and Dong Mingming construct the dynamic game model among three parties and construct the profit distribution model in urban renewal based on the Sharply value method [8]. 


\section{The Relationship among Stakeholders}

As the acceleration of our country's economic growth, the main stakeholders of urban renewal gradually separate to three cliques, including the government, developer, and residents. They are linked together by all kinds of problems produced during the process of urban renewal and their profits are associated but contradictory [2].Their relationship is showed in figure 1.

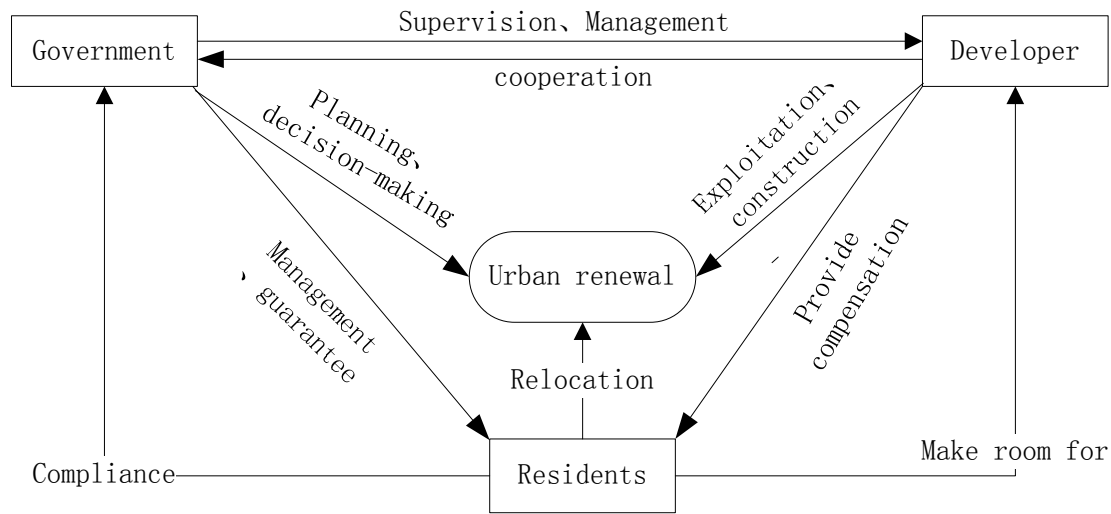

Fig.1 The relationship among stakeholders

\section{The profit game between developer and residents}

The developer and residents represent their own profit during the process of housing demolition in urban renewal, so they contest with each other in profit game to expect their own profit increase.

Only two opinions are hypothesized between developer and residents about the compensation measures: agreement or disagreement. It supposes that the profits which the residents gained are $A$, and the developer gained are $B$. According to the provision, the developer should pay compensation for residents, marked as $a$, so the profits of residents now are $A+a$, and those of developer are $B-a$. However, if residents agree with this plan while developer disagrees that, due to the assignment of urban renewal still need to complete, their profits are still $A$ and $B$. The third situation is that if developer agrees with this plan while residents disagree with that. The residents hope to add more compensation based on $A+a$, marked as $b$. So the profits of residents are $A+a+b$ while that of developer are $B-a-b$. The last situation which is the worst is that the two parties all disagree with compensation measure, so that they must via the law to solve the problem. Therefore, two parties should pay for the cost caused by court, marked as $c$. Moreover, the developer postpones the construction progress, so that it may engenders more cost, marked as $d$. The profits of residents become $A-c$, and those of developer are $B-c-d$ which are greater than $a+b$ when developer compromise to the plan. The profits is showed in table 1.

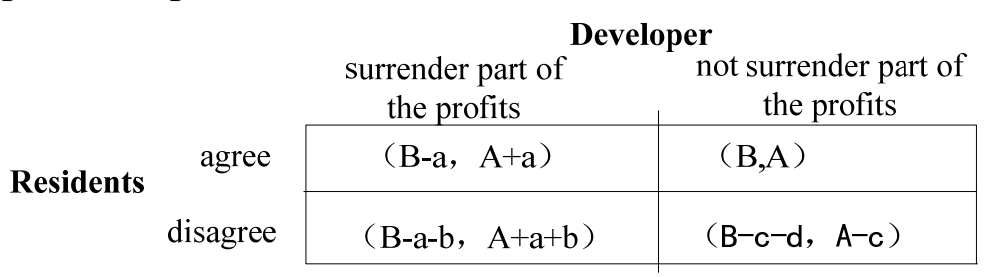

Table 1 Profit matrix between developer and residents

According to analyze the profit matrix, the agreement of developer can lead to higher profits for residents, so that the longer the time the residents drag on, the higher the profits they gained. As a result, people who known this knack may become what we called nail household. Moreover, the agreement of residents can make developer slash the compensations so that gain the higher profits. The developer hopes complete the housing demolition as soon as possible to conduct the subsequent projects, so that they may use the violent means for demolishing [5]. The two parties should avoid the situation that both of them are disagree with the plan, since this situation can cause both of them lose. 


\section{The profit game among developer, residents and government}

The background of the construction of game model: According to the above analysis, if simply analyze the profit game between two stakeholders (developer and residents), obviously, they may all pursue their own profits maximization which can lead to the internecine situation. Therefore, the government should formulate relevant policies and play the role of supervision in order to make the result of housing demolition reasonable.

A game model among government, developer and residents is constructed, based on the reference of the above game model that between developer and residents. In order to maintain the stability of society and achieve the target of fairness and efficiency during the process of housing demolition, government requires developer surrender part of the profits to residents, marked as $y$. As the concessive behavior of developer, government also renders some appropriate compensation to developer, marked as $x$. Otherwise the developer can use his superiority to slash the residents' profits, just like the above game model. Moreover, the government should pay some costs for supervision, marked as $z$. Since the profits distribution become equilibrium that will lead to the stability of society and a good social image, the government can receive some potential profits, marked as $m$. Obviously, $m>x>y>z$, and only in this way the social total welfare can increase.

Based on the theory of reciprocating fairness, the game parties consider not only the material profits, but also the psychological value brought by fairness. If all of stakeholders consider the social fairness, they may voluntarily give up some material profits to realize the harmonious result [8]. The situation supposed is that the government chooses supervision and the developer chooses surrender part of the profits, so they can obtain a larger psychological value, marked as $K$ and $N$. To the contrary, they can lose a larger psychological value, marked as $-K$ and $-N$. If only one party want to express the sense of fairness, the party can obtain a smaller psychological value, marked as $k$ or $n$, while the other party can lose a smaller psychological value, marked as $-k$ or $-n$.

\section{Analysis of game equilibrium based on reciprocating fairness theory under the complete information condition}

Under the complete information condition, the government can make a judgment that whether the developer surrender part of profits to residents or not, even though the government do not supervise developer. Their profits matrixes indicate in table 2.

\begin{tabular}{|c|c|c|c|c|c|}
\hline \multirow{4}{*}{$\begin{array}{c}\text { Residents } \\
\text { disagree }\end{array}$} & \multicolumn{2}{|c|}{ Developer } & & \multicolumn{2}{|c|}{ Developer } \\
\hline & $\begin{array}{l}\text { Surrender part of } \\
\text { the profits }\end{array}$ & $\begin{array}{l}\text { Not surrender part of } \\
\text { the profits }\end{array}$ & & $\begin{array}{l}\text { Surrender part of } \\
\text { the profits }\end{array}$ & $\begin{array}{l}\text { th surrender part of } \\
\text { the profits }\end{array}$ \\
\hline & $(\underline{\mathrm{K}-\mathrm{z}-\mathrm{x}} \cdot \underline{\mathrm{N}+\mathrm{x}-\mathrm{y}}, \underline{\mathrm{y}})$ & $(\underline{\mathrm{k}-\mathrm{z}}, \underline{-\mathrm{n}}, 0)$ & afree & 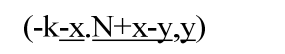 & $(-\mathrm{K}, \underline{-\mathrm{N}}, 0)$ \\
\hline & 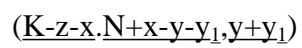 & $(\mathrm{K}-\mathrm{z},-\mathrm{n}-\mathrm{c}-\mathrm{d},-\mathrm{c})$ & disagree & $\left(-\mathrm{k}-\underline{x} \cdot \underline{N}+x-y-y_{1}, y+y_{1}\right)$ & $(-\mathrm{K},-\mathrm{N}-\mathrm{c}-\mathrm{d},-\mathrm{c})$ \\
\hline
\end{tabular}

Table 2 The static game among three parties under the complete information condition

Based on the profits matrixes showed above, it is not difficult to see that whether developer surrender part of the profits or not and whether residents agree or disagree this behavior, if the larger psychological value and the smaller psychological, generated by government's supervision, support the relation: $K-z-x>-k-x$ or $K>z-k$ (According to the above analysis, the relation: $K .>x>y>z$ is known, so the relation: $K-z-x>-k-x$ is correct), there is one Nash Equilibrium among three game parties : (supervise, surrender part of the profits, agree)

\section{Analysis of game equilibrium based on reciprocating fairness theory under the incomplete information condition}

Under the incomplete information condition, if government doesn't supervise the developer, he cannot observe the behavior that whether the developer surrender part of profits to residents. Therefore, the developer has the motivation not to surrender part of profits to residents, or even use 
his superiority as far as possible to deprive the profits of residents. Their profits matrixes indicate in table 3.

\begin{tabular}{|c|c|c|c|c|c|}
\hline \multirow{3}{*}{$\begin{array}{r}\text { agree } \\
\text { disagree }\end{array}$} & $\begin{array}{l}\text { Surrender part of } \\
\text { the profits }\end{array}$ & $\begin{array}{l}\text { Not surrender part of } \\
\text { the profits }\end{array}$ & \multirow{3}{*}{$\begin{array}{r}\text { Residents } \\
\text { disagree }\end{array}$} & \multicolumn{2}{|c|}{$\begin{array}{cc}\begin{array}{c}\text { Surrender part of } \\
\text { the profits }\end{array} & \begin{array}{c}\text { Not surrender part of } \\
\text { the profits }\end{array}\end{array}$} \\
\hline & $(\underline{\mathrm{K}-\mathrm{z}-\mathrm{x}} \cdot \underline{\mathrm{N}+\mathrm{x}-\mathrm{y}, \mathrm{y})}$ & $(\underline{\mathrm{k}-\mathrm{z}}, \underline{-\mathrm{n}}, 0)$ & & $(-\mathrm{k}-\underline{x} \cdot \underline{\underline{N}+\mathrm{x}-\mathrm{y}}, \underline{\mathrm{y}})$ & $(-\mathrm{K},-\underline{\mathrm{N}+\mathrm{x}}, 0)$ \\
\hline & 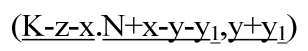 & $(K-z,-n-c-d,-c)$ & & $\left(-\mathrm{k}-\underline{x} \cdot \underline{N+x-y-y_{1}}, \underline{y}+y_{1}\right)$ & $(-\mathrm{K},-\mathrm{N}-\mathrm{c}+\mathrm{X}-\mathrm{d},-\mathrm{c})$ \\
\hline
\end{tabular}

Table 3 The static game among three parties under the incomplete information condition

According to the above analysis, the relation: $K-z-x>-k-x$ is correct, the Pure Strategy Nash Equilibrium is as same as above: (supervise, surrender part of the profits, agree). Consequently, the game equilibrium can increase the social welfare and reduce the cost of housing demolition, so that make the social public profits maximization.

\section{The Evaluation Criteria of Profits Distribution among Stakeholders}

The root of contradiction of urban renewal is profit. Every party hope to gain the maximum profits, but sometimes you cannot sell the cow and drink the milk. At least one party need to compromise so that an evaluation principle is needed to distribute the profits among stakeholders regularly. Through establishing the evaluation criteria, a distinct and optimum decision for the urban renewal is made. Some credible professors are invited to grade the items which related to the three parties (government, developer and residents) in the process of urban renewal. The average score multiply to weight, and then compared with each other so that we can obtain an optimum way for distributing the profits. The evaluation concepts are in table 4.

\begin{tabular}{|c|c|c|c|c|}
\hline Stakeholders & Number & Concept & Score & Weight \\
\hline \multirow{4}{*}{ The profits of government } & $\mathrm{a}_{1}$ & Improve the urban environment & & $\mathrm{q}_{1}$ \\
\cline { 2 - 5 } & $\mathrm{a}_{2}$ & Optimize function space & & $\mathrm{q}_{2}$ \\
\cline { 2 - 5 } & $\mathrm{a}_{3}$ & Protect the historical architecture & & $\mathrm{q}_{3}$ \\
\hline & $\mathrm{a}_{4}$ & Obtain the grant fee of land & & $\mathrm{q}_{4}$ \\
\hline & $\mathrm{a}_{5}$ & Transfer to infrastructure construction & & $\mathrm{q}_{5}$ \\
\cline { 2 - 5 } & $\mathrm{a}_{6}$ & Guarantee the profits distribution of & & \multirow{2}{*}{\begin{tabular}{c}
$\mathrm{q}_{6}$ \\
\cline { 2 - 5 }
\end{tabular}} \\
\cline { 2 - 5 } & $\mathrm{a}_{7}$ & Maintain the stability of society & & $\mathrm{q}_{7}$ \\
\hline \multirow{2}{*}{ The profits of developer } & $\mathrm{a}_{8}$ & Gain the maximum profits & & $\mathrm{q}_{8}$ \\
\hline \multirow{4}{*}{ The profits of residents } & $\mathrm{a}_{9}$ & Improve the living standard & & $\mathrm{q}_{9}$ \\
\hline & $\mathrm{a}_{10}$ & Obtain the value-added of space & & $\mathrm{q}_{10}$ \\
\hline
\end{tabular}

Table 4 The evaluation concepts of profits distribution

Each item is graded by authoritative experts, and then the mean of the score is calculated. Each item's weight is determined by its importance in urban renewal.

For instance, there are $n$ appraisable agencies participate in the evaluation plan for urban renewal. They grade the item of the profits of government (improve the urban environment), and the scores are $\mathrm{a}_{11}, \mathrm{a}_{12}, \mathrm{a}_{13} \ldots \mathrm{a}_{1 \mathrm{n}}$, and the rest can be done in the same manner, so the score of the last item in the above table are $\mathrm{a}_{101}, \mathrm{a}_{102}, \mathrm{a}_{103} \ldots \mathrm{a}_{10 \mathrm{n}}$. As the weights of every item are $\mathrm{q}_{1}, \mathrm{q}_{2}, \mathrm{q}_{3} \ldots \mathrm{q}_{10}$, the total score of every agency is calculated as equation (1):

$$
\begin{aligned}
& \mathrm{A}_{j}=\frac{\sum_{\mathrm{i}=1}^{10} \mathrm{a}_{\mathrm{ij}} \cdot \mathrm{q}_{\mathrm{i}}}{10} \quad(j=1,2 、 3 \ldots \mathrm{n}) \\
& A=\max \left(A_{1}, A_{2}, A_{3} \cdots A_{n}\right)
\end{aligned}
$$

According to the above calculation, the scheme which has the highest scores (A) is the best choose for urban renewal. The profits distribution can make judgment for the feasibility of scheme of urban renewal. 


\section{Conclusions}

The study of the paper shows that the relationships among the government, the developer and the original residents in an urban renewal project are contradictory while mutually beneficial: both of the developer and the residents hope to gain their maximum profits and government hopes to get her political prestige enhanced. Therefore, through constructing the game model of fair reciprocity, game equilibrium among the government, the developer and the residents is found. The conclusion is that the developer should surrenders part of profits to residents. Meanwhile, government should supervise this behavior that developer surrenders part of profits and residents accept the compensation reasonable. This conclusion can lead to a cooperative equilibrium and a win-win-win situation.

Based on the consequence, the evaluation criteria of profits distribution among stakeholders are proposed. These criteria can provide a theoretical foundation for distributing profits among stakeholders and consummating the compensation mechanism so that selecting the best scheme for urban renewal. However, due to the space constraints, this criterion is proposed just as a preliminary idea, the weight of items should take a further research so that make the analysis more perfect.

\section{References}

[1] Liu Li, Zou Yi. Eight dilemmas of urban renewal [J]. City pictorial, 2007(9):150-151

[2] Wang Da. Analysis on compulsory execution of urban house demolition [J]. Legal Application, 2003(11):56-58

[3] Zhu Dongkai, Shi Guoqing. Analysis on the benefits relationship of the earth expropriation for urban construction and relocation of residents [J]. Urban Studies, 2004, 11(3):23-26

[4] Zhang Bo. Game interests among stakeholders in urban village renovation [J]. Shan Xi Architecture, 2009, 35(22):17-18

[5] Yao Yanhong. Game analysis on urban house demolition and the countermeasures [D]. Xi an University of Architecture and Technology, 2007

[6] Kahneman,D, A. Tversky. Prospect theory: An Analysis of decision under risk [J]. Econometrica, 1979(47):63-91

[7] Guo Bin. The model construction of profits distribution in the process of urban renewal [J]. Pioneering with Science \& Technology, 2009(4): 116-117

[8]Sun Shizhe. The development of fairness game theory and the introduction of several game models [J]. Economic and Financial Circles, 2007(9):250-251 